\title{
Gold Nanoshelled Liquid Perfluorocarbon Magnetic Nanocapsules: a Nanotheranostic Platform for Bimodal Ultrasound/Magnetic Resonance Imaging Guided Photothermal Tumor Ablation
}

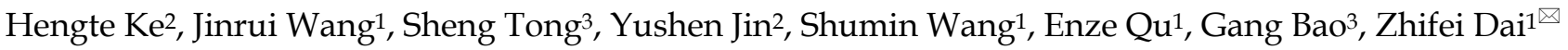 \\ 1. College of Engineering and Peking University Third Hospital, Peking University, Beijing 100871, China; \\ 2. Nanomedicine and Biosensor Laboratory, School of Life Science and Technology, Harbin Institute of Technology, Harbin 150001, China. \\ 3. Department of Biomedical Engineering, Georgia Institute of Technology and Emory University, Atlanta, Georgia 30332, USA.
}

$\triangle$ Corresponding author: Email: zhifei.dai@pku.edu.cn.

() Ivyspring International Publisher. This is an open-access article distributed under the terms of the Creative Commons License (http://creativecommons.org/ licenses/by-nc-nd/3.0/). Reproduction is permitted for personal, noncommercial use, provided that the article is in whole, unmodified, and properly cited.

Received: 2013.07.28; Accepted: 2013.10.01; Published: 2013.12.01

\begin{abstract}
Imaging guided ablation therapy has been applied in both biomedical research and clinical trials and turned out to be one of the most promising approaches for cancer treatment. Herein, the multifunctional nanocapsules were fabricated through loading perfluorooctylbromide (PFOB) and superparamagnetic iron oxide nanoparticles (SPIOs) into poly(lactic acid) (PLA) nanocapsules (NCs), followed by the formation of PEGylated gold nanoshell on the surface. The resulting multi-component NCs were proved to be able to act as nanotheranostic agent to achieve successful bimodal ultrasound (US)/magnetic resonance imaging (MRI) guided photothermal ablation in human tumor xenograft models non-invasively. Such a single theranostic agent with the combination of real-time US and high-resolution MR imaging would be of great value to offer more comprehensive diagnostic information and dynamics of disease progression for the accurate location of therapeutic focusing spot in the targeted tumor tissue, showing great potential as an effective nanoplatform for contrast imaging guided photothermal therapy.
\end{abstract}

Key words: Liquid perfluorocarbon nanocapules, Superparamagnetic iron oxide nanoparticles, Gold nanoshell, Bimodal imaging, Photothermal therapy.

\section{Introduction}

Photothermal therapy (PTT) utilizing near-infrared (NIR) lasers and photoabsorbers has gained popularity recently as a non-invasive and remote-control alternative to conventional surgery and chemotherapy.[1-3] Nevertheless, three typical challenges must be overcome to achieve the highly efficient PTT: (1) how to identify the accurate location and size of tumors as well as the presence of photoabsorbers for laser irradiation before therapy; (2) how to monitor the treatment procedure in real-time during therapy to ensure complete eradication of microscopic tumor; (3) how to assess the effectiveness after therapy. The integration of contrast-enhanced diag- nostic imaging capability with photothermal therapy could be the choice of modalities to carry out these tasks.

Gold nanoshell has a spherical dielectric core particle and a thin nano-scale gold shell around. By controlling the thickness of the gold shell and the diameter of the core, the plasmon resonance and the resulting optical absorption of gold nanoshells can be tuned to the NIR region, where the absorption of human tissues is minimal and penetration is optimal.[4-7] Therefore, the NIR-absorbed gold nanoshells can be used as photoabsorbers for remote NIR photothermal ablation therapy. In our previous 
study, we achieved ultrasound guided PTT using gold nanoshelled microcapsules (GNS-MCs) developed by forming a gold nanoshell around the surface of UCA based on poly(lactic acid) (PLA) microcapsules.[7] However, the GNS-MCs still encountered two main obstacles: (1) the diameter of GNS-MCs $(2.32 \pm 1.07 \mu \mathrm{m})$ is too large to pass through the vessels feeding the tumor; (2) the spatial and anatomical resolution of US imaging is relatively poor.

In clinic, two or more biomedical imaging techniques are usually applied together to reach more reliable diagnostic results, since each imaging technique has its specific advantages as well as limitations. Therefore, in the recent years, the idea of using multimodal imaging modalities in combination has attracted the attention of researchers.[8] Typically, diagnostic ultrasound (US) imaging and magnetic resonance imaging (MRI) are now the two representative imaging and diagnosis modalities for imaging-guided tumor ablation.[9-12]. US imaging shows advantages due to its features of real-time, low cost, high safety and readily availability for portable devices. However, the spatial and anatomical resolution of US images is relatively poor compared to other imaging methods. The disadvantages of US might be overcome by the integration of MRI, which has been applied in clinic for the diagnosis of many diseases due to its excellent spatial and anatomical resolution, nonionizing radiation and high sensitivity to the distribution of water and other biomolecules.[13-15] Therefore, the combination of US and MRI imaging capabilities integrated with PTT could achieve a multifunctional theranostic platform for bimodal imaging guided and monitored photothermal tumor ablation.

Recent advancement in nanomaterial preparation has brought about a significant impact for potential clinical applications in both diagnostics and therapeutics.[16-18] Perfluorocarbons (PFCs) with unique properties such as high oxygen solubility, low surface tension, hydrophobicity and lipophobicity, inertness and absence of metabolism, safety and biocompatibility, have been developed for various medical purposes.[19, 20] Because of their high difference of density with air and their poor solubility in water, liquid PFCs such as perfluorooctyl bromide (PFOB) have been encapsulated in the biodegradable and biocompatible polymeric shells to prepare nano-scale ultrasound contrast agents (UCAs) with great stability and echogenicity.[21, 22] Besides, the superparamagnetic iron oxide nanoparticles (SPIOs) are widely applied $\mathrm{T}_{2}$-weighted MRI contrast agents, which can provide a safe and strong negative contrast enhancement of the target lesion in MRI due to their high susceptibility and biocompatibility.[23-29]

In this paper, our basic idea is to upgrade gold nanoshelled microcapsules to nano-scale theranostic agents for bimodal US/MRI contrast imaging guided photothermal tumor ablation by incorporating two extra components of SPIOs and PFOB into the biodegradable polymer PLA nanocapsules with additional PEGylation in order to accomplish more efficient photothermal tumor ablation. The SPIOs-embedded PFOB nanocapsules with PEGylated gold shells were synthesized via an adapted oil-in-water $(\mathrm{O} / \mathrm{W})$ emulsion solvent evaporation process,[21] followed by the formation of gold nanoshells using a surface seeding method [30] and surface PEGylation using methoxy-poly(ethylene glycol)-thiol (Figure 1A). It is expected that sufficient agent accumulation in diseased areas can be achieved by replacing microcapsules with nano-scale capsules as well as PEGylation to help NCs escape the rapid clearance from the bloodstream to increase the circulation time and reinforce the enhanced permeability and retention (EPR) effect.[31-34] SPIOs were used to get more accurate diagnostic information from contrast-enhanced MRI images. PFOB with well-documented safety and biocompatibility $[19,20]$ can provide great US contrast enhancement both in vitro and in vivo.[19-22] Such a single nanotheranostic agent with the combination of US and MR imaging would be of great value to offer more comprehensive diagnostic information and the dynamics of disease progression for more accurate location of the therapeutic focusing spot in the targeted tumor tissue for more effective tumor ablation (Figure 1B).

\section{Materials and Methods}

\section{Materials}

Poly(lactic acid) (PLA, 80k MW, Shandong Medical Instrumental Institute, China), polyvinyl alcohol (PVA, 86-89\% hydrolyzed, low molecular weight, Alfa Aesar), perfluorooctyl bromide (PFOB, J\&K Scientific Ltd., China), hydroxylamine hydrochloride $\left(\mathrm{NH}_{2} \mathrm{OH} \cdot \mathrm{HCl}\right.$, Shanghai Shanpu Chemical, China), thiol-terminated methoxypoly(ethylene glycol) (mPEG5000-SH, 5k MW, Beijing Kaizheng Biotech Development Co. Ltd., China), poly(allylamine hydrochloride) (PAH, 56k MW, Sigma-Aldrich) were used as received. Hydrogen tetra-chloroaurate (III) hydrate $\left(\mathrm{HAuCl}_{4} \cdot 4 \mathrm{H}_{2} \mathrm{O}\right)$, sodium citrate, sodium borohydride $\left(\mathrm{NaBH}_{4}\right)$ and oleic acid were obtained from SinoReagent, China. Deionized water (DI water, 18.2 $\mathrm{M} \Omega \cdot \mathrm{cm}$ ) from Milli-Q Gradient System was used in all the preparations. 

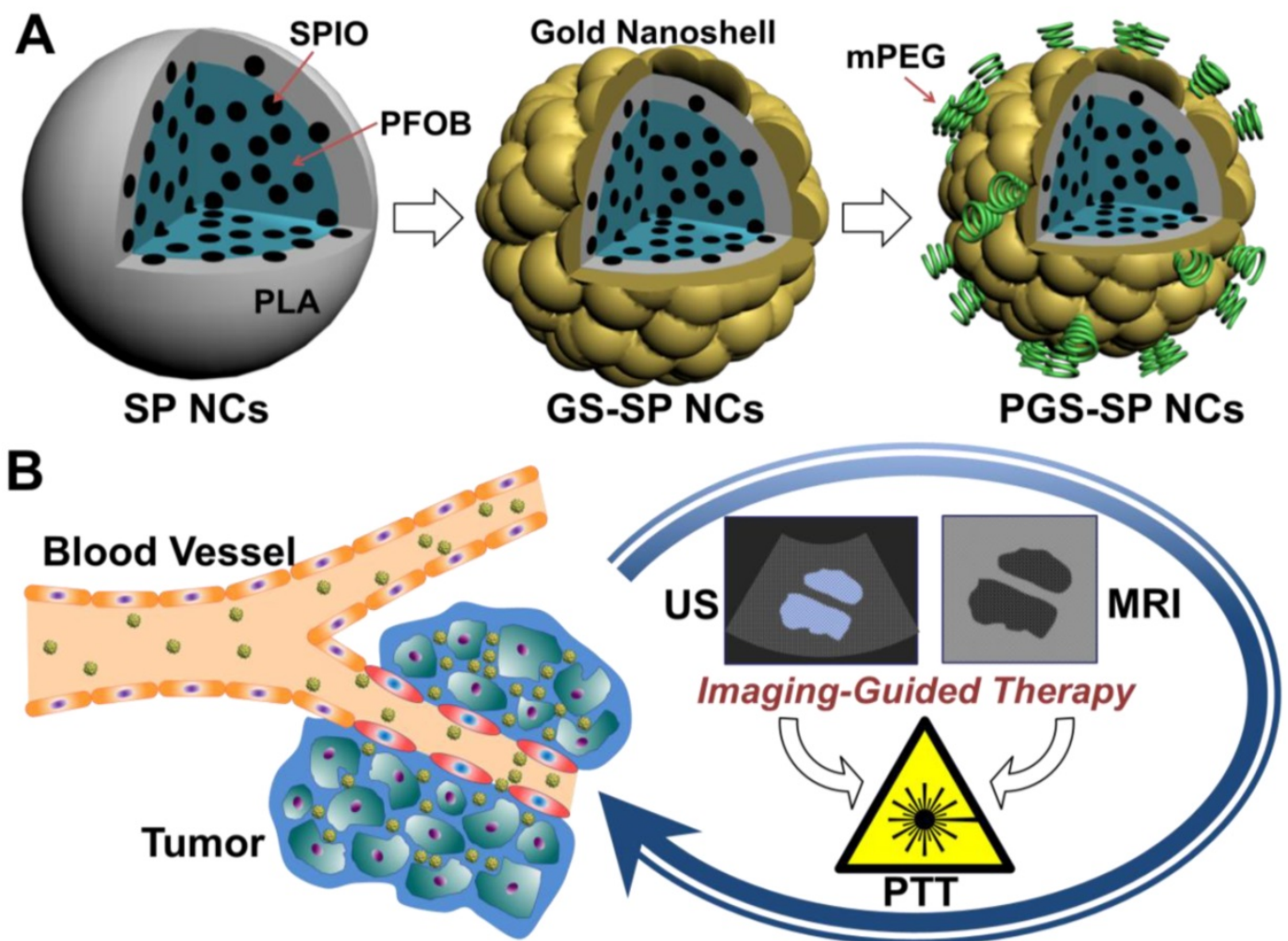

Fig I. (A) Schematic illustration of the fabrication procedure of PGS-SP NCs; (B) The biomodal US/MRI guided tumor PTT process using the nanotheranostic agent.

\section{Gold Nanoparticle and Iron Oxide Nanoparti- cle Preparation}

Citrate-stabilized gold nanoparticles (GNPs) were prepared according to the previous report.[35] $\mathrm{HAuCl}_{4}$ aqueous solution $(12.7 \mathrm{~mL}, 10 \mathrm{mM})$ was added into DI water $(87.3 \mathrm{~mL})$ with vigorous stirring for $1 \mathrm{~min}$, followed by the addition of sodium citrate solution $(1.0 \mathrm{~mL}, 5 \% \mathrm{w} / \mathrm{v})$. Another one minute later, $\mathrm{NaBH}_{4}(1.0 \mathrm{~mL}, 0.375 \% \mathrm{w} / \mathrm{v})$ in sodium citrate $(5 \%$ $\mathrm{w} / \mathrm{v}$ ) solution was added and continuously stirred for $5 \mathrm{~min}$, and then stored at $4{ }^{\circ} \mathrm{C}$ until needed.

Oleic acid-stabilized superparamagnetic iron oxide nanoparticles (SPIOs) were generated by a co-precipitation method.[36] $\mathrm{FeCl}_{3} \cdot 6 \mathrm{H}_{2} \mathrm{O}(0.5 \mathrm{M})$ and $\mathrm{FeSO}_{4} \cdot 7 \mathrm{H}_{2} \mathrm{O}(0.5 \mathrm{M})$ were dissolved by DI water $(100$ $\mathrm{mL}$ ) in a four-neck flask, followed by adding $\mathrm{NH}_{3} \cdot \mathrm{H}_{2} \mathrm{O}$ solution $(30 \mathrm{~mL})$ at room temperature under $\mathrm{N}_{2}$ atmosphere. The aqueous solution was heated to $80{ }^{\circ} \mathrm{C}$ for $30 \mathrm{~min}$, and oleic acid was added in with vigorous stirring for another $30 \mathrm{~min}$. The precipitate was isolated by an Nd-Fe-B magnet and washed 3 times with DI water and 3 times with acetone, and dispersed in hexane for use.

\section{Nanocapsule Fabrication}

The polymer PLA $(100 \mathrm{mg})$ and PFOB $(0.1 \mathrm{~mL})$ were dissolved in $3.5 \mathrm{~mL}$ methylene chloride, and oleic acid-stabilized SPIOs in hexane $\left(20 \mathrm{mg} \mathrm{mL}^{-1}, 0.5\right.$ $\mathrm{mL}$ ) were added and well mixed. SPIO-embedded PFOB nanocapsules (SP NCs) were prepared by an adapted oil-in-water $(\mathrm{O} / \mathrm{W})$ emulsion solvent evaporation process.[21] The $\mathrm{O} / \mathrm{W}$ emulsion was generated by adding the oil phase to the PVA aqueous solution $(2 \% \mathrm{w} / \mathrm{v}, 20 \mathrm{~mL})$ followed by continuous probe sonication for $120 \mathrm{~s}$ with a $1.27 \mathrm{~cm}(1 / 2 \mathrm{inch})$ diameter titanium alloy horn (Sonicator 4000, Misonix) under $80 \%$ output amplitude setting. Afterwards, the emulsion was magnetic stirred at room temperature for $2 \mathrm{~h}$ to evaporate almost all the methylene chloride. Then, the nanocapsules were collected by centrifugation (15000 g at $15{ }^{\circ} \mathrm{C}$ for $5 \mathrm{~min}$, Avanti J-25, Beckman Coulter) and washed with DI water.

The nanocapsule suspension $(100 \mu \mathrm{L})$ was added in PAH solution $\left(8 \mathrm{~mL}, 1.0 \mathrm{mg} \mathrm{mL}^{-1}\right.$ in $0.5 \mathrm{M} \mathrm{NaCl}$ aqueous solution) in a $10 \mathrm{~mL}$ vial, shaken and mixed for about $15 \mathrm{~min}$, then centrifuged at $15000 \mathrm{~g}$ for 5 min. The supernatant was discarded and excessive non-adsorbed PAH molecules were washed by DI water for 3 times. Then, citrate-stabilized GNP solution $(8 \mathrm{~mL})$ was added in and the adsorption/centrifuge/wash step was repeated to obtain the gold nanoparticle coated SP NCs (GP-SP NCs).

After that they were re-dispersed and poured 
into $\mathrm{HAuCl}_{4}(16 \mathrm{~mL}, 2.5 \mathrm{mM})$ under magnetic stirring. Then, freshly prepared $\mathrm{NH}_{2} \mathrm{OH}$ solution $(0.67 \mathrm{~mL}, 400$ $\mathrm{mM}$ ) was added dropwise and stirred for about 30 min to allow the reduction of $\mathrm{HAuCl}_{4}$ to form nanoshells around the capsule surface. The resulting gold nanoshelled nanocapsules (GS-SP NCs) were centrifuged and re-dispersed in mPEG5000-SH $(8 \mathrm{~mL}$, $0.01 \mathrm{mg} \mathrm{mL}^{-1}$ ) and stirred for $1 \mathrm{~h}$. At last, the centrifuged PEGylated GS-SP NCs (PGS-SP NCs) were lyophilized $\left(-54{ }^{\circ} \mathrm{C}, 36 \mathrm{~h}\right)$ by using a freeze dryer (TFD5505, Ilshin Lab, Korea), sealed and stored at $4^{\circ} \mathrm{C}$.

\section{Nanocapsule Characterization}

The morphology of SP NCs and PGS-SP NCs was observed by FEI Quanta 250 FEG scanning electron microscope (SEM). The corresponding energy dispersive X-ray spectroscopy of the samples (without gold sputtering process) was performed with a liquid nitrogen-cooled $\mathrm{Si}(\mathrm{Li})$ detector that was attached to SEM to verify the elements of the resulted nanocapsules. Transmission electron microscopic (TEM) images of SP NCs and PGS-SP NCs were acquired by FEI Tecnai G2 Sphera Microscope with a CCD camera operated at $100 \mathrm{kV}$ to confirm the structure and the successful fabrication of gold nanoshell. The UV-visible extinction spectra of SP NCs, GP-SP NCs, GS-SP NCs and PGS-SP NCs were analyzed by a UV-visible spectrophotometer (Varian Cary 4000) with a quartz cuvette of $1 \mathrm{~cm}$ optical path length to monitor the fabrication progress and ensure the high absorption in NIR region. Size distributions of SP NCs and PGS-SP NCs were analyzed through dynamic light scattering using a particle size distribution analyzer (Brookhaven ZetaPALS). The amount of Fe and $\mathrm{Au}$ elements in PGS-SP NCs was determined by inductively coupled plasma atomic emission spectroscopy (ICP-AES, PerkinElmer Optima 5300 DV).

\section{In Vitro and In Vivo Imaging}

In vitro US imaging: In vitro ultrasonography of PGS-SP NCs was carried out in the latex tube (with the inner diameter of $\sim 5 \mathrm{~mm}$ ) using Acuson S2000 Ultrasound System unit with a 9L4 transducer (Siemens Healthcare). The PGS-SP NCs were dispersed in $0.9 \%$ saline at the concentration of $5 \mathrm{mg} \mathrm{mL}^{-1}$ and injected to the latex tube. Ultrasonography was performed using the transducer in both pulse inversed harmonic imaging (PIHI) mode (mechanical index, $\mathrm{MI}=0.61$ ) and conventional B-mode at the same time and the contrast-enhanced images were acquired from the longitudinal cross section of the tube.

In vivo US imaging: For in vivo study, three rabbits (average weight of $3.8 \mathrm{~kg}$ ) were anesthetized with pentobarbital sodium $(2.0 \mathrm{~mL}$ per $\mathrm{kg}$ weight, $2 \% \mathrm{w} / \mathrm{v}$ in $0.9 \%$ saline) administration through ear vein, and subsequently, heparin sodium $(4.0 \mathrm{~mL}, 0.2 \% \mathrm{w} / \mathrm{v}$ in $0.9 \%$ saline) was injected to avoid coagulation. The animals were placed on a warm blanket to keep body temperature within normal range during the experiment. The PGS-SP NCs suspension $\left(40 \mathrm{mg} \mathrm{mL}^{-1}\right.$ in $0.9 \%$ saline) was intravenously injected at a concentration of $0.1 \mathrm{~mL}$ per $\mathrm{kg}$ weight through a catheter, flushed with saline $(1.0 \mathrm{~mL})$ thereafter. The kidney was imaged transabdominally using the transducer in PIHI mode with MI of 0.70 . All the digital clips and images were stored for off-line review. All the animal experiments were approved by institutional animal use committee and carried out ethically and humanely.

In vitro MR imaging: PGS-SP NCs were suspended in PBS at different Fe concentrations $(0,4.97$, 9.93, 19.9, 39.7, $9.93 \mu \mathrm{M})$ and $\mathrm{T}_{2}$-weighted $\mathrm{MR}$ images of the samples were collected by a 7 Tesla Bruker Small Animal MRI instrument $(\mathrm{FOV}=3 \mathrm{~cm} \times 3 \mathrm{~cm}$; Matrix $=256 \times 256$; $\mathrm{TR}=750 \mathrm{~ms}$; $\mathrm{TE}=60 \mathrm{~ms}$; Pulse sequence: MSME). The corresponding $\mathrm{T}_{2}$ of the samples were measured at 0.47 Tesla by Bruker MQ20 Minispec Analyzer for the calculation of the $\mathrm{T}_{2}$ relaxivity.

\section{Biocompatibility and Photothermal Effect}

Cell toxicity evaluation of PGS-SP NCs was carried out on HUVECs (human umbilical vein endothelial cells). HUVEC cells $\left(10^{4}\right.$ cells per well) were incubated in 96 -well plates at $37^{\circ} \mathrm{C}$ for $24 \mathrm{~h}$. Different dosage $\left(0.2 \mathrm{~mL}\right.$ per well, from 0 to $\left.0.5 \mathrm{mg} \mathrm{mL}^{-1}\right)$ of PGS-SP NCs suspensions were added in and incubated with cells for $24 \mathrm{~h}$. Then the cell viabilities were determined by MTT (3-(4,5-dimethylthiazol-2-yl) -2,5-diphenyltetrazoliumbromide) assay. Results are shown as mean \pm standard deviation $(S D)(n=3)$.

Photohyperthermic effect of PGS-SP NCs was assessed via monitoring temperature increase under the laser irradiation. The agent of different concentrations was suspended in quartz cuvettes (total volume of $0.5 \mathrm{~mL}$ ), irradiated by continuous-wave fiber-coupled diode NIR laser (T808F2W, Xi' an Minghui Optoelectronic Technology, China) with a center wavelength of $808 \pm 10 \mathrm{~nm}$ and output power of $2 \mathrm{~W}$ for $10 \mathrm{~min}$. The temperature of the solutions was measured by a digital thermometer with a thermocouple probe every $10 \mathrm{~s}$.

In vitro cytoviability assay of PGS-SP NCs combined with NIR laser was also carried out. HeLa cells (human cervical carcinoma cell line, $10^{4}$ cells per well) were incubated in $96-$ well plates at $37^{\circ} \mathrm{C}$ for $24 \mathrm{~h}$. Different dosage ( $0.2 \mathrm{~mL}$ per well, from 0 to $\left.0.2 \mathrm{mg} \mathrm{mL}^{-1}\right)$ of PGS-SP NCs suspensions were added in and incubated with cells for $4 \mathrm{~h}$. Then, the cells were irradiated 
by NIR laser $\left(808 \mathrm{~nm}, 6.67 \mathrm{~W} \mathrm{~cm}^{-2}\right.$ ) for $6 \mathrm{~min}$ and the cell viabilities were determined by MTT assay. Results are shown as mean \pm standard deviation (SD) $(n=3)$.

\section{Bimodal Imaging Guided Tumor Ablation}

Cell culture: The HT-1080 (human sarcoma cell line) tumor cell line was maintained in DMEM medium supplemented with $10 \%$ heat inactivated fetal bovine serum, $100 \mathrm{U} \mathrm{mL}^{-1}$ penicillin and $100 \mathrm{~g} \mathrm{~mL}^{-1}$ streptomycin, and $2 \mathrm{mM}$ L-glutamine at $37^{\circ} \mathrm{C}$ in an atmosphere of $5 \% \mathrm{CO}_{2}$ in air. The tumor cells were routinely subcultured twice a week by trypsin-EDTA treatment. The cells growing in an exponential growth phase will be harvested and counted for tumor inoculation.

Animals: Balb/c nude mice, female, 6-8 weeks, weigh approximately 18-22g. 32 (24 mice plus $25 \%$ spare) mice for HT-1080 were purchased from Peking University Health Science Center of Laboratory Animal Science (PUHSCLAS, Beijing, China). All the animal experiments were approved by institutional animal use committee and carried out ethically and humanely.

Tumor inoculation: $2 \times 10^{6}$ HT-1080 tumor cells with $0.1 \mathrm{~mL}$ of PBS were injected in the right front flank of the mice until the tumor size reaches as large as approximately $729 \mathrm{~mm}^{3}$ for better development of tumor vessels. Tumor sizes were measured twice weekly in two dimensions using a caliper, and the volume will be expressed in $\mathrm{mm}^{3}$ using the formula: $\mathrm{V}$ $=0.5 \times a \times b^{2}$ (where $a$ and $b$ are the long and short diameters of the tumor, respectively). The body weight of each mouse was also measured twice a week and expressed in $\mathrm{g}$.

Imaging guidance: PGS-SP NCs $\left(200 \mu \mathrm{L}, 2 \mathrm{mg} \mathrm{mL}^{-1}\right.$ suspension in saline) were intratumorally injected locally into the tumors of the mice for US contrast imaging guidance. The tumors then were imaged via the 9L4 transducer of Acuson S2000 US Imaging System before, during and after the injection of the agent. For MRI guidance, the agent $\left(150 \mu \mathrm{L}, 2 \mathrm{mg} \mathrm{mL}^{-1}\right.$ suspension in saline) was intravenously administrated into the tumors. $\mathrm{T}_{2}$-weighted MR images of the tumors were imaged by the 7 Tesla Bruker Small Animal MRI instrument (Spin-echo sequence, $\mathrm{TR}=1500$ $\mathrm{ms}, \mathrm{TE}=12,24, \ldots, 120 \mathrm{~ms})$ at different time points $(0$, $0.5,1,2,4,24 \mathrm{~h}$ ) post-injection of the agent.

Tumor ablation: HT-1080 xenografted nude mice were divided into 4 groups with 6 mice in each group: control group, agent-only group, laser-only group and agent+laser group. PGS-SP NCs $(150 \mu \mathrm{L}, 2 \mathrm{mg}$ $\mathrm{mL}^{-1}$ suspension in saline) were intravenously administrated for agent-only and agent+laser groups, while saline $(150 \mu \mathrm{L})$ was injected in control and laser-only groups, respectively. The laser irradiation treatment was performed $1 \mathrm{~h}$ after the injection with NIR laser $\left(808 \mathrm{~nm}, 1.30 \mathrm{~W} \mathrm{~cm}^{-2}\right)$ exposure to the tumor sites for $10 \mathrm{~min}$. The tumors in laser-only group would take the same laser irradiation. Treatment was carried out twice at day 0 and day 4 for all the 4 groups after the first therapy.

Statistical analysis: Results are presented as mean \pm s.d.. The mean difference in tumor growth delay and body weight change between control group and other groups was analyzed by the Student's $t$ test, with $p<0.05$ considered to be statistically significant.

\section{Results and Discussion}

\section{Nanocapsule Characterization}

The first step for upgrading our previous gold nanoshelled microcapsules[7] is to decrease the capsule size from micro-scale to nano-scale. Continuous probe sonication was applied for oil-in-water emulsion process instead of homogenization to obtain nanocapsules.[21] The typical morphology and structure of SP NCs and PGS-SP NCs were characterized by SEM and TEM. The SP NCs without gold coating showed well-defined spherical shape with smooth surface with the average diameter of $300.4 \pm 75.7 \mathrm{~nm}$ (Figure 2A, B). PGS-SP NCs kept their spherical shape after gold shell formation but exhibited rough surface morphology (Figure 3A) and their average diameter increased to about $373.6 \mathrm{~nm}$ (Figure 3D). In the magnified SEM and TEM images (Figure $3 B, C)$, aggregated gold particles with diameters of tens of nanometers were clearly seen on the surface of PGS-SP NCs, suggesting the successful fabrication of gold nanoshells. The deep grey spots could be observed from the TEM micrograph inside the SP NCs, indicating the encapsulation of SPIOs in the nanocapsules (Figure 2C). Furthermore, the energy dispersive X-ray spectroscopy (EDS) of PGS-SP NCs showed the large amount of additional Au element, compared to the SP NCs with element presence of only $\mathrm{C}, \mathrm{O}, \mathrm{F}, \mathrm{Br}$ and Fe also suggesting the successful nanocapsule fabrication and encapsulation of PFOB and SPIOs (Figure 2D). The amount of $\mathrm{Fe}$ and $\mathrm{Au}$ element in PGS-SP NCs was $3.73 \%$ and $43.00 \%$ in weight, respectively, measured by ICP-AES. 

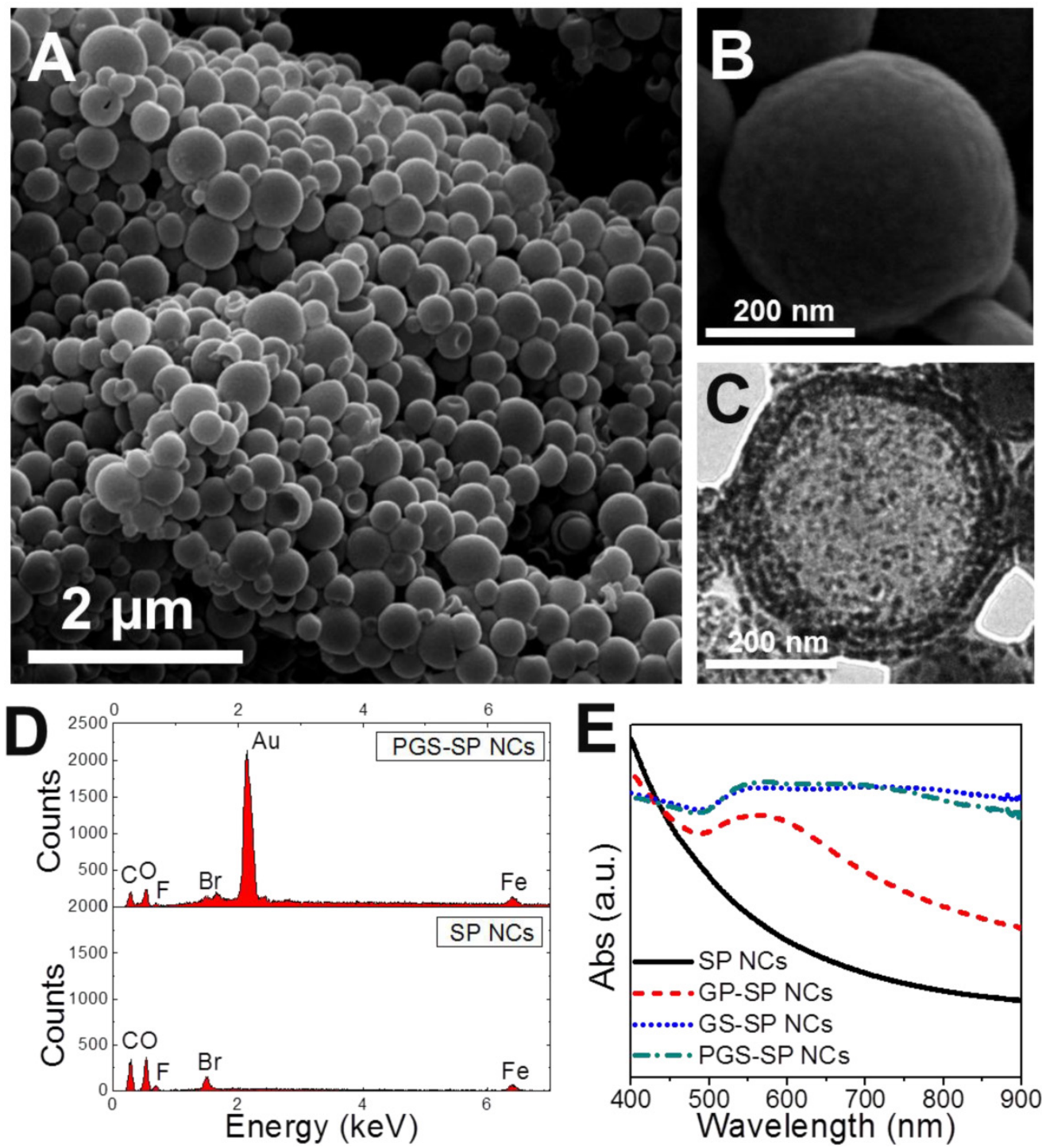

Fig 2. (A, B) SEM images of the SP nanocapsules; (C) TEM images of SP NCs; (D) EDS spectrum comparison of SP NCs and PGS-SP NCs; (E) UV-vis spectra of the agent at different stages of fabrication process.
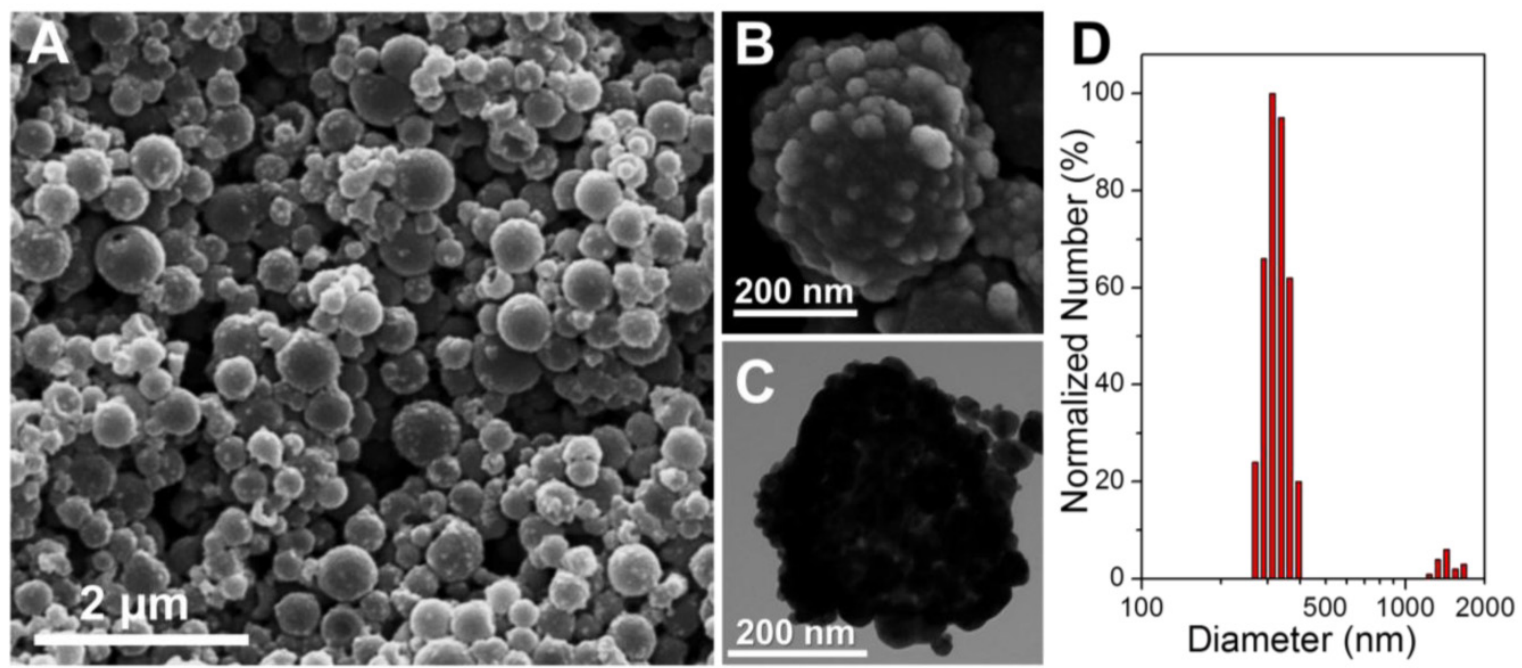

Fig 3. (A, B) SEM images of the PGS-SP nanocapsules; (C) TEM images of the agent; (D) Size distribution of the theranostic agent. 
To monitor the preparation progress, UV-visible extinction spectra of samples at different fabrication stages were examined (Figure 2E). The spectrum of SP NCs exhibited no obvious peak in the range from 400 $\mathrm{nm}$ to $900 \mathrm{~nm}$. After the deposition of gold nanoseeds onto the surface of SP NCs, the plasmon resonance increased to form a peak around 500 600 nm. The seeding process made the attached gold nanoparticles grown larger enough to cluster, leading to a continuous broad peak ranging from 550 to $850 \mathrm{~nm}$. The red shift and broad plasmon resonance peak of gold species could be attributed to the wider size distribution and non-uniform aggregation of the gold nanoparticles on the surface.[37] The PEGylation resulted in a little difference in the spectrum of PGS-SP NCs due to the change of refractive index of the surroundings. The broad absorbance in NIR region ensured the obtained nanocapsules could serve as photoabsorbers for effective tumor photohyperthermia.

\section{Functionality Assessment}

As the structure and physical properties had been verified, the functionalities of the nanotheranostic agent of PGS-SP NCs were examined. The bimodal contrast enhanced imaging capabilities of the nanocapsules were analyzed in vitro first. The US contrast enhancement of the nanocapsules was verified in a latex tube in PIHI mode. The latex tube was flexible and the ultrasound beam could penetrate the tube wall to stimulate the contrast agents in the lumen to get harmonic signals for contrast-enhanced imaging. The unique nonlinear harmonic signal generated by UCAs under the clinical ultrasound scanning could be extracted from the echo and processed by PIHI (pulse inverted harmonic imaging) to display the contrast-enhanced images. In PIHI mode, two successive pulses with opposite sign are emitted and then subtracted from each other. This implies that any linearly responding constituent will disappear while UCAs with non-linear compressibility will stand out to display a contrast-enhanced image by the processing of the clinical ultrasound diagnostic system.[38] Using clinical US imaging system, significant contrast had be generated in the presence of PFOB-encapsulated polymeric nanocapsules in the PIHI mode as previous reported in the literature (Figure 4A).[20] That indicated the formation of gold nanoshell on the surface and encapsulation of SPIOs in the liquid PFC nanocapsules had little influence on the echogenic property of the resulted capsules. On the other hand, the nanocapsules exhibited excellent increasing contrast enhancement along with the rise of the concentration as shown in the $\mathrm{T}_{2}$-weighted $\mathrm{MR}$ images (Figure $4 \mathrm{C}$ ) with high $\mathrm{T}_{2}$ relaxivity of $395.7 \pm 8.0$ $\mathrm{mM}^{-1} \mathrm{~s}^{-1}$ calculated from Minispec Analyzer at $0.47 \mathrm{~T}$
(Figure 4B), which is more than 2 times as high as that of commercial SPIO-based MRI contrast agent Resovist $\left(185.8 \pm 9.3 \mathrm{mM}^{-1} \mathrm{~s}^{-1}\right)$,[39] ensuring good MRI contrast enhancement. The higher $\mathrm{T}_{2}$ relaxivity was probably due to the aggregation of SPIOs in the nanocapsules, leading to relatively enlarged size of the magnetic nanoparticles, which could increase the $\mathrm{T}_{2}$ relaxivity.[23] The capability of photothermal conversion was verified by monitoring the temperature increase of PGS-SP NC suspensions under the irradiation of NIR laser. Under a continuous-wave laser with a center wavelength of $808 \mathrm{~nm}$ and output power of $2 \mathrm{~W}$, the temperature of $0.5 \mathrm{~mL}$ nanocapsule suspension in a quartz cell at different concentrations was collected every $10 \mathrm{~s}$ (Figure 4D). The temperature elevation was as high as $32.9^{\circ} \mathrm{C}$ when the concentration reached up to $0.5 \mathrm{mg} \mathrm{mL}^{-1}$, while there was only $3.9^{\circ} \mathrm{C}$ increasement for the DI water itself. That suggested that the nanocapsule suspension at relatively low concentration could be easily heated up to above $42{ }^{\circ} \mathrm{C}$, which can kill tumor cells at this level of temperature,[40] making PGS-SP NCs an efficient photoabsorber for photothermal therapy of cancer.

The biocompatiablity of PGS-SP NCs was studied by culturing HUVECs with different concentrations of nanocapsules. The cells remained more than $90 \%$ of their viability even when the dosage was up to $0.5 \mathrm{mg} \mathrm{mL}^{-1}$ (Figure 5A), indicating the good biocompatiablity of the resulting nanocapsules could ensure their use as novel theranostic agent for further cell experiments and in vivo application. The evaluation of photothermal hyperthermia effect on HeLa cells showed that the cancer cells exhibited a significant decrease of cell viabilities along with the increasing concentration only when treated with the agent PGS-SP NCs plus NIR laser irradiation (Figure 5B). HeLa cells treated with the agent without laser irradiation remained more than $80 \%$ viable cells even when the dosage was up to $0.1 \mathrm{mg} \mathrm{mL}^{-1}$, suggesting the composite agent itself had little impact on cell survival at high concentration. On the contrary, there was a significant decrease of cell viabilities along with the increasing concentration while the cancer cells were treated with the agent suspension under laser irradiation. When the cells were treated laser irradiation with the agent at concentration from 0.01 to 0.1 $\mathrm{mg} \mathrm{mL}-1$, their viabilities decreased rapidly. Only less than $10 \%$ of the HeLa cells remained viable when incubated with $0.1 \mathrm{mg} \mathrm{mL}^{-1}$ agent under NIR irradiation, suggesting markedly photothermal therapeutic effect. The result confirmed that the combination of PGS-SP NCs with NIR laser could kill the tumor cells via photohyperthermia effectively, making the nanotheranostic agent a potential candidate for photothermal tumor ablation. 
Using the clinical ultrasound imaging system, the kidney of the rabbit showed obvious enhancement at the PIHI contrast mode in the MI of 0.70 several seconds after the bolus intravenous injection of the agent PGS-SP NCs $\left(0.1 \mathrm{~mL} \mathrm{~kg}^{-1}, 40 \mathrm{mg} \mathrm{mL}^{-1}\right)$ (Figure 5C). The mechanical index (MI) is an estimate of the maximum amplitude of the pressure pulse in tissue. It is an indicator for the degree of mechanical bioeffects. The FDA ultrasound regulations allow a MI of up to
1.9 to be used for applications for the biosafety concern. In our experiment, a relatively high MI of larger than 0.6 could get US contrast-enhanced images with PGS-SP NCs. During the in vivo tests on rabbits, the vital sign of animals was smooth during the entire procedure, and no arrhythmia or other side effects were observed, indicating the agents showed no evidence of acute toxicity, which was consistent with the biocompatibility result on HUVECs (Figure 5A).
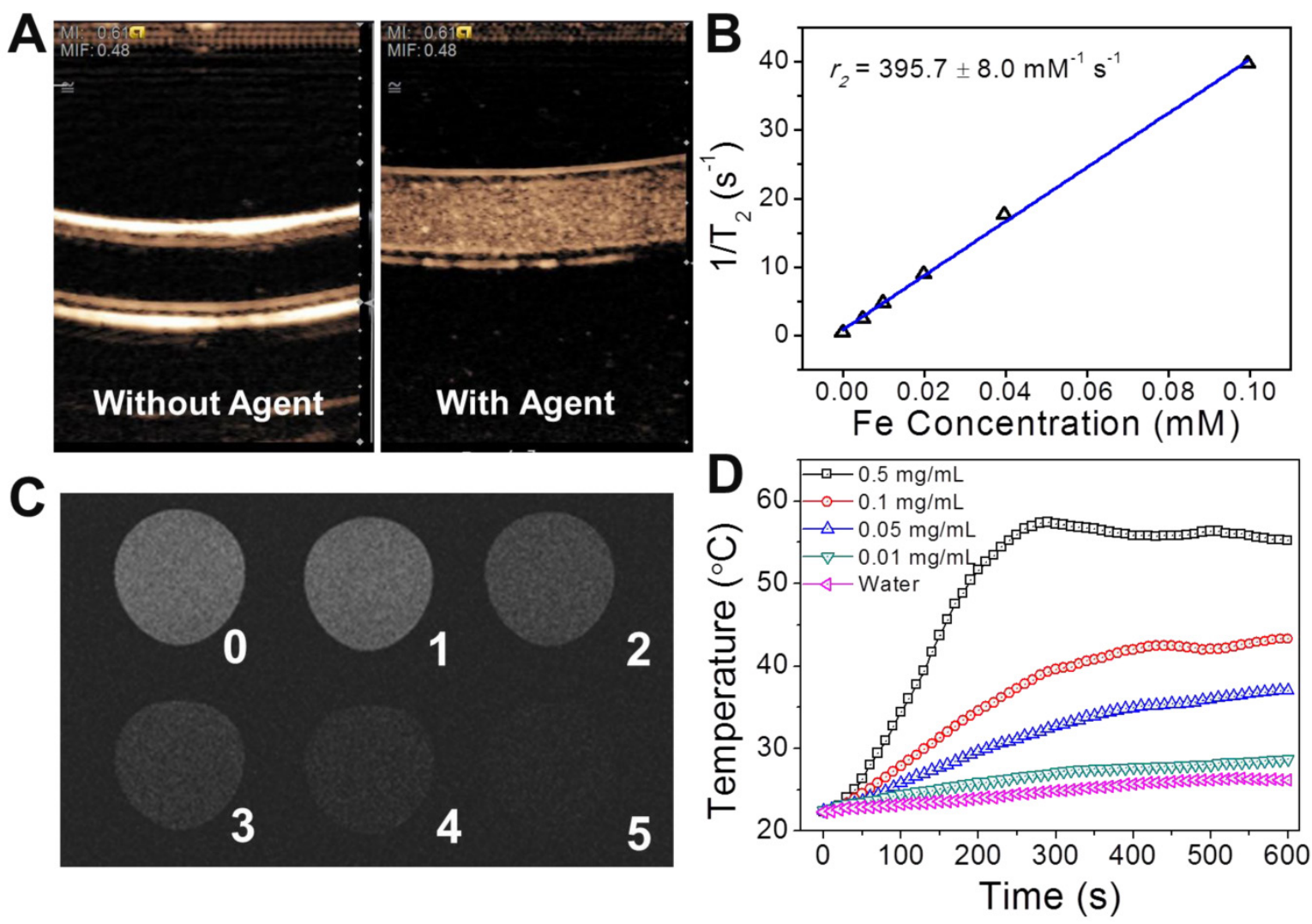

Fig 4. (A) Contrast enhanced US imaging at PIHI mode in the latex tube without and with the nanocapsule suspension; (B) The water proton transvers relaxation rate $\left(\mathrm{T}_{2}{ }^{-1}\right)$ of PGS-SP NCs measured by a $0.47 \mathrm{~T}$ minispec analyzer as a function of Fe concentration; (C) in vitro $\mathrm{T}_{2}$-weighted $\mathrm{MR}$ contrast images of the agent at different concentrations (TE = $60 \mathrm{~ms}$; Fe concentration of sample 0 5: 0, 4.97, 9.93, 19.9, 39.7, 9.93 $\mu \mathrm{M})$ under a $7 \mathrm{~T}$ MRI instrument; (D) temperature increase of PGS-SP NC suspension at different concentrastions under NIR laser irradiation (The thermometer probe was carefully placed in the top of the suspension for temperature monitoring to avoid the direct irradiation of NIR laser, which could dramatically affect the measurement.).
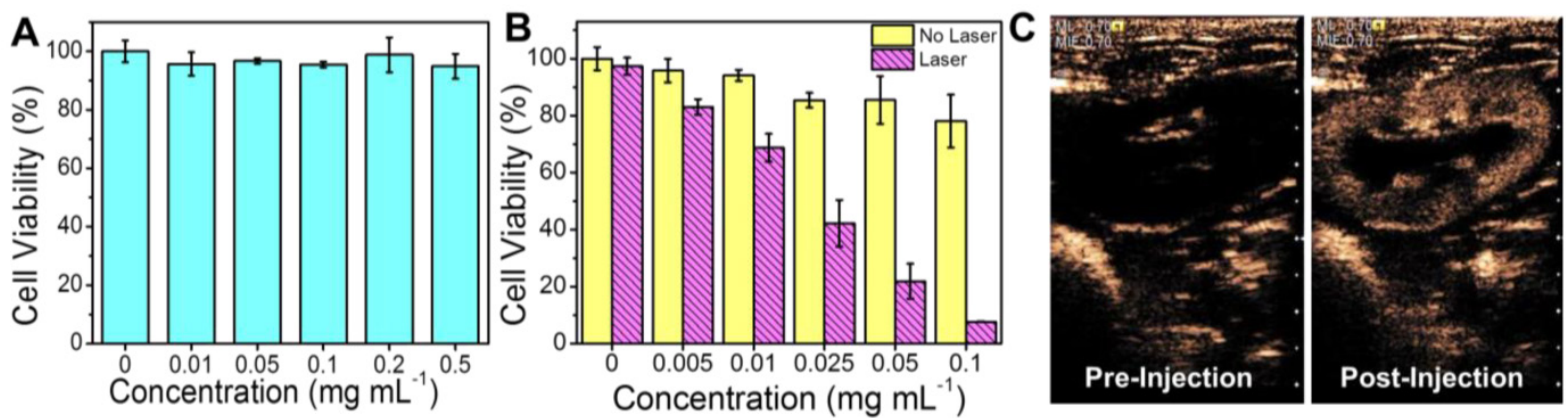

Fig 5. (A) Cell viabilities of HUVECs at different dosages of the agent (0, 0.0I, 0.05, $0.1,0.2,0.5 \mathrm{mg} \mathrm{mL}^{-1}$, data expressed as mean \pm s.d.); (B) Cell viabilities of HeLa of PGS-SP NCs at different dosages $\left(0,0.005,0.01,0.025,0.05,0.1 \mathrm{mg} \mathrm{mL}^{-1}\right)$ with or without NIR laser irradiation $\left(808 \mathrm{~nm}, 6.67 \mathrm{~W} \mathrm{~cm}^{-2}, 6 \mathrm{~min}^{2}\right.$ data expressed as mean \pm s.d..); (C) Contrast enhanced US imaging at PIHI mode in rabbit kidney before and after intravenously injection of $0.1 \mathrm{~mL} \mathrm{~kg}^{-1} 40$ $\mathrm{mg} \mathrm{mL}^{-1}$ of the agent $(\mathrm{Ml}=0.70)$. 


\section{Imaging Guided Tumor Ablation}

The biomodal US/MRI contrast imaging guided phototherml tumor ablation was performed on nude mouse xenograft models. US imaging guidance was perfomed under the real-time monitoring using clinical US imaging system (Figure 6A). In order to ablate the entire tumor, it is critical to make sure that the agent infiltrate the entire tumor mass. The tumor was firstly found and shown in the conventional
B-mode, and no ultrasonographic enhancement was observed before injection. Then the imaging mode was changed to PIHI contrast mode, and in contrast the boundary and size of the tumors can be clearly detected in real-time after the agent injection, suggesting that US imaging can help ensure the complete distribution of the photoabsorber to guide the following photo ablation therapy.
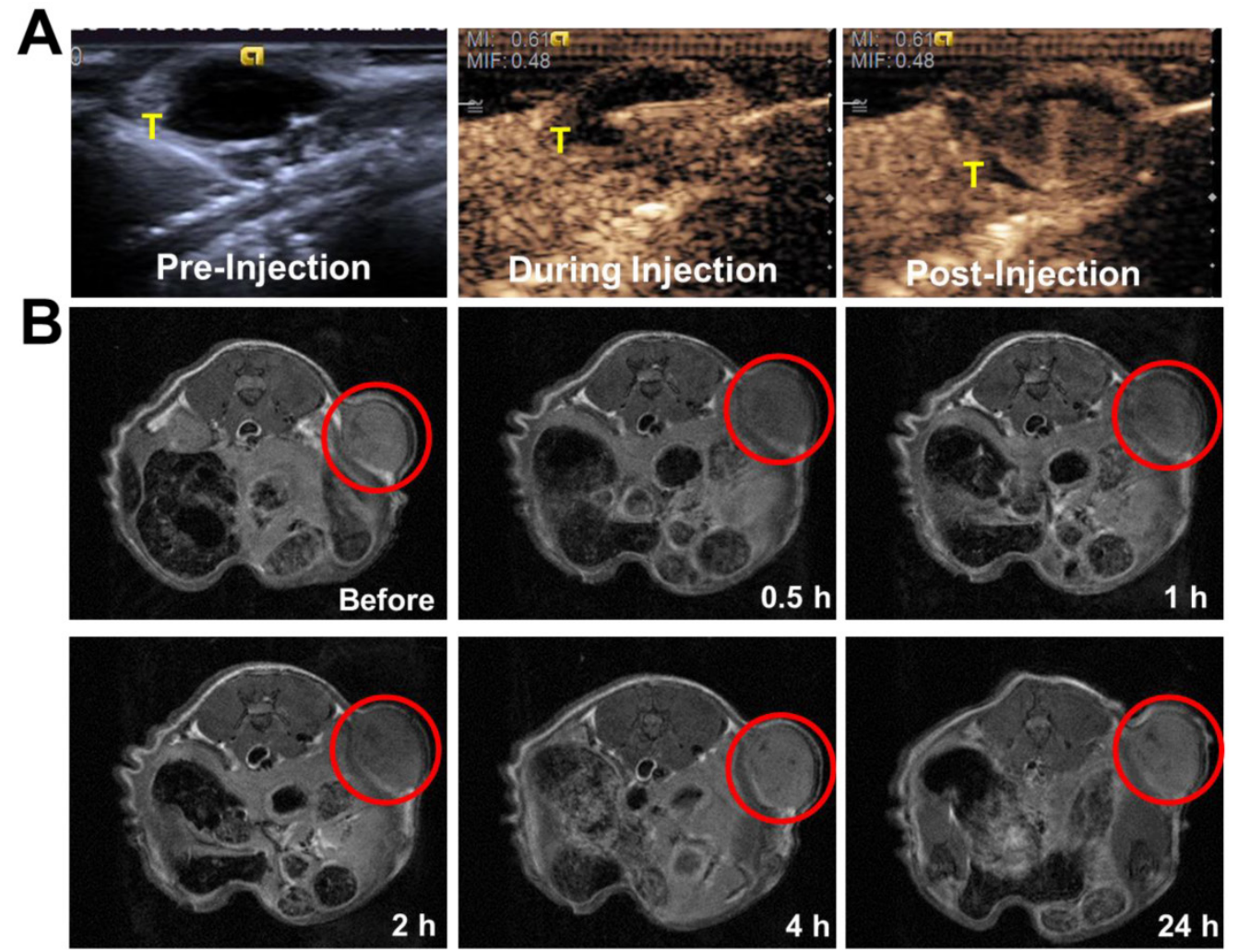

C

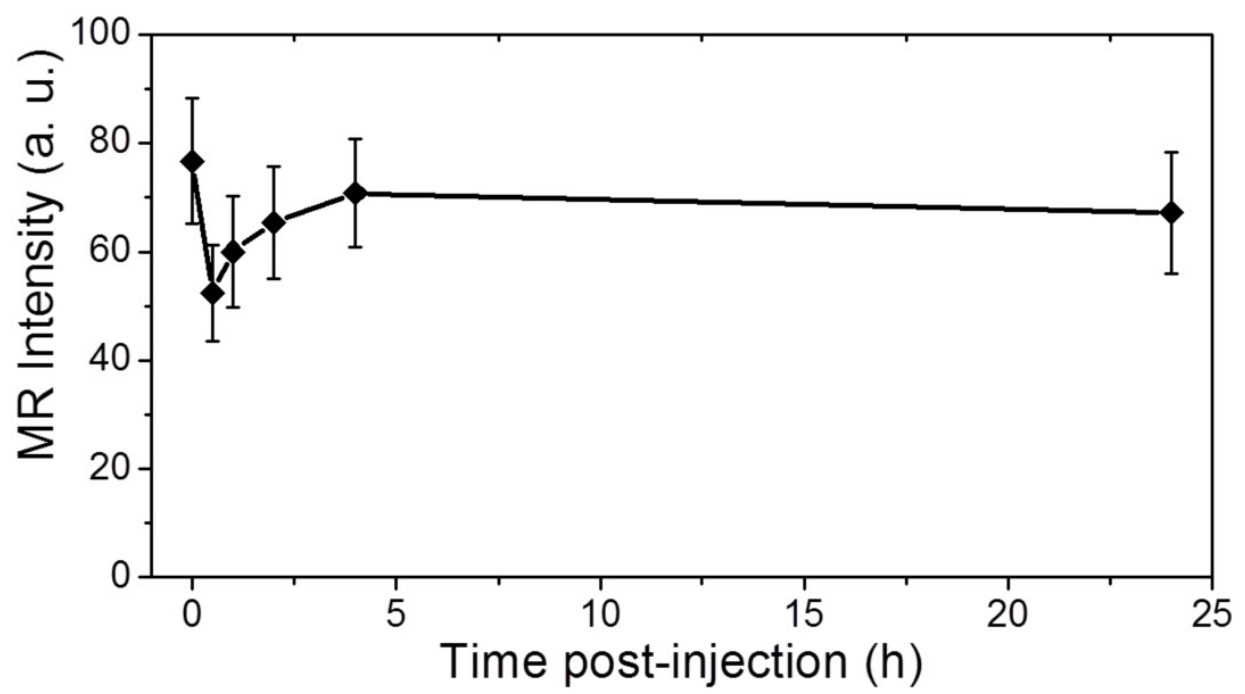

Fig 6. (A) Contrast-enhanced ultrasonograms before, during and after the intratumoral injection of the agent ( $\left.0.2 \mathrm{~mL}, 2 \mathrm{mg} \mathrm{mL}^{-1}\right)$ into the mice for visualization of the agent distribution to guide the following therapy (tumors highlighted by $T$ ); ( $B$ ) $T_{2}$-weighted MR images of the tumors at different time points after intravenously injection of the agent $\left(0.15 \mathrm{~mL}, 2 \mathrm{mg} \mathrm{mL}^{-1}\right)$ for visualization of tumor areas to guide the following photothermal ablation (tumors are highlighted in the red circles); (C) MR intensity changing profile of the tumors from tumor-bearing mice at different time points post intravenous administration of the nanocapsules. 
The agent of PGS-SP NCs could be not only used for the guidance under US contrast imaging, but also applicable via intravenous administration to targetly accumulate in the tumor sites for MRI guidance due to the EPR effect. The abnormalities in the tumor tissue lead to higher permeability of tumor vessels to the PGS-SP NCs compared with normal vessels, and the impaired clearance of the nanocapsules from the interstitial space of the tumor (due to longer retention of nanocapsules, which could be enhanced via PEGylation) could result in targeted accumulation on tumor sites.[34] $\mathrm{T}_{2}$-weighted $\mathrm{MR}$ images of the transverse section of tumor-bearing mice were acquired before and at different time points after the intravenous administration of PGS-SP NCs (Figure 6B). The MR contrast imaging displayed the xenografted tumor as grey area inside the red circle before the intravenous administration of nanocapsule suspension. When the agent was injected intravenously into the tumor bearing mice, the nanocapsules tended to accumulate in the tumor sites due to EPR effect, which was enhanced by the nanoscaled size and the surface PEGylation of the nanocapsules. The tumor turned to be obviously darkened $0.5 \mathrm{~h}$ later, suggesting the SPIO functionalized nanocapsules had been aggregated in the tumor site to generate negative contrast in the $\mathrm{T}_{2}$-weighted MR image. The average MR intensity in the tumor area calculated from the MR image decreased rapidly by $31.6 \%$ from $76.7 \pm 11.6$ to $52.4 \pm 8.9$ (Figure 6C), showing the significant negative enhancement due to the nanocapsule aggregation. For images taken from $1 \mathrm{~h}$ and $2 \mathrm{~h}$ after injection, the enhancement in the tumor was still clear, which was consistent with the MR intensity calculation. The images at $4 \mathrm{~h}$ and $24 \mathrm{~h}$ didn't show obvious contrast compared with image of $2 \mathrm{~h}$, suggesting the nanocapsules had been gradually cleared from the tumor. The images of $0.5 \mathrm{~h}, 1 \mathrm{~h}$ and $2 \mathrm{~h}$ after injection the tumor sites exhibited obvious decrease in $\mathrm{T}_{2}$-weighted $\mathrm{MR}$ intensity signal compared with the image before injection, indicating the nanocapsules could successfully accumulate and remain in the tumor sites as long as two hours to provide adequate time for the following therapy. The targeted accumulated nanocapsules also can display the tumor areas to guide the NIR laser irradiation for photothermal ablation of tumors without damaging the surrounding healthy tissues.

The photothermal tumor ablation therapy was carried out since the capabilities of bimodal US/MRI contrast imaging guidance had been verified. HT-1080 tumor-bearing nude mice were divided into 4 groups with 6 mice in each group: control group, agent-only group, laser-only group and agent+laser group. PGS-SP NCs (150 $\mu \mathrm{L}, 2 \mathrm{mg} \mathrm{mL}^{-1}$ suspension in saline) were intravenous injected into the mice of agent-only and agent+laser groups, while saline $(150 \mu \mathrm{L})$ in control and laser-only groups, respectively. Then, the tumor-bearing mice of laser-only and agent+laser groups with continuous anesthesia were placed under the NIR laser ( $\left.808 \mathrm{~nm}, 1.30 \mathrm{~W} \mathrm{~cm}^{-2}, 10 \mathrm{~min}\right)$ with exposure spot right on the tumor areas for treatment. The treatment for each group was carried out twice and the therapeutic effectiveness was estimated by the tumor volume measurement (Figure 7A). Inoculated tumors in control, agent-only and laser-only groups grew rapidly, with no significant difference in final tumor sizes. The result indicated that the tumor growth could not be affected by either PGS-SP NCs or NIR laser irradiation alone. Unlike the other 3 groups, tumors in agent+laser group deceased from $709 \pm 83.49$ $\mathrm{mm}^{3}$ to $444 \pm 227 \mathrm{~mm}^{3}$ on the 9th day after treatment (34.0\% smaller in tumor size). Compared with control group (2499 $\pm 230 \mathrm{~mm}^{3}$ at day 9), the tumor growth was inhibited by $82.2 \%$, suggesting that sufficient accumulation of PGS-SP NCs could trigger the great photothermal effect locally for effictive photothermal tumor ablation. Furthermore, the photographs of the representative mice from the different 4 groups were recorded before and after the treatment, showing the visualized excellent therapeutic effectiveness of agent+laser group compared to the other three groups (Figure 7C).

Body weight loss was used as a measure of treatment induced toxicity (Figure 7B). By day 9, the mice in 4 groups had a little decrease in their body weight, but the result showed no significantly difference compared with each other, demonstrating that all treatments incluing intravenous injection of the agent and photo-induced hyperthermia were tolerated well by the tumor-bearing animals and the photothermal treatment showed no unacceptable toxicity.

Table I. Statistical analysis of different treatment on HT-I080 xenograft model.

\begin{tabular}{lllll}
\hline Group & $\begin{array}{l}\text { Tumor size } \\
\text { after treatment } \\
\left(\mathrm{mm}^{3}\right)\end{array}$ & $\begin{array}{l}\mathrm{p} \text { value } \\
(\mathrm{v} . s . \text { con- } \\
\text { trol })\end{array}$ & $\begin{array}{l}\text { Body weight } \\
\text { after treat- } \\
\text { ment }(\mathrm{g})\end{array}$ & $\begin{array}{l}\mathrm{p} \text { value } \\
\text { (v.s. con- } \\
\text { trol) }\end{array}$ \\
\hline control & $2499 \pm 230$ & - & $21.8 \pm 0.8$ & - \\
agent-only & $2422 \pm 268$ & 0.831 & $21.1 \pm 0.9$ & 0.583 \\
laser-only & $2011 \pm 528$ & 0.389 & $23.3 \pm 1.5$ & 0.298 \\
agent+laser & $444 \pm 227$ & $8.19 \times 10^{-5} *$ & $21.2 \pm 0.9$ & 0.542 \\
\hline
\end{tabular}



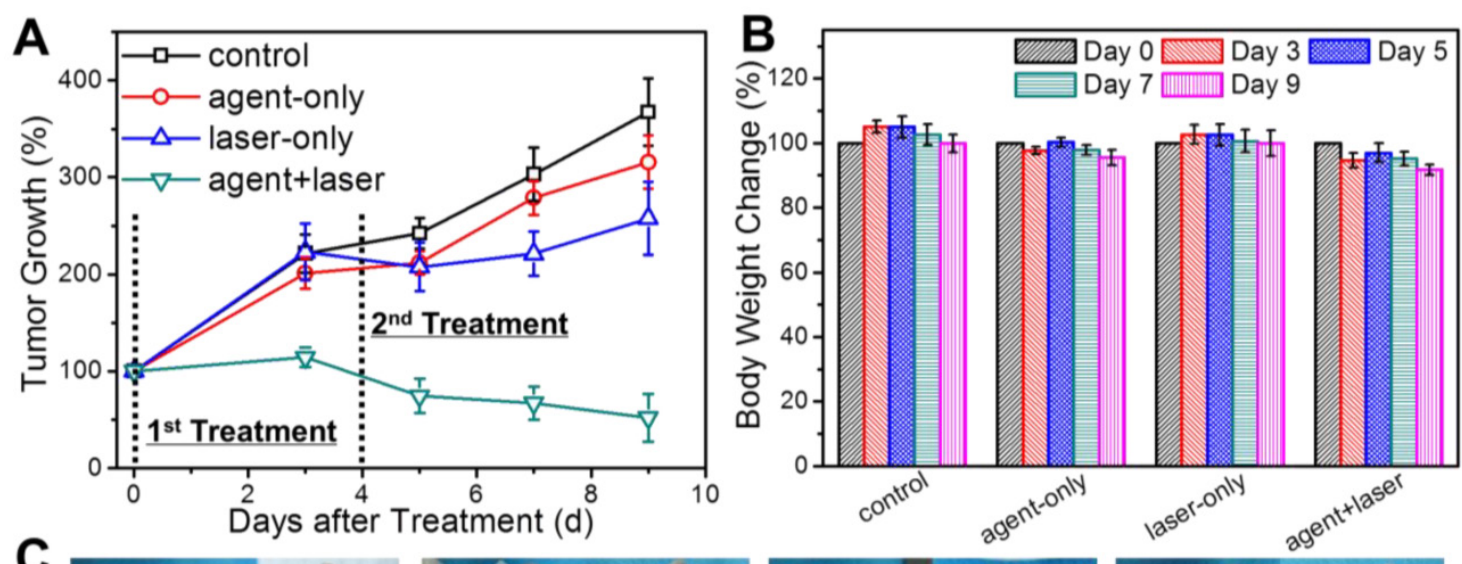

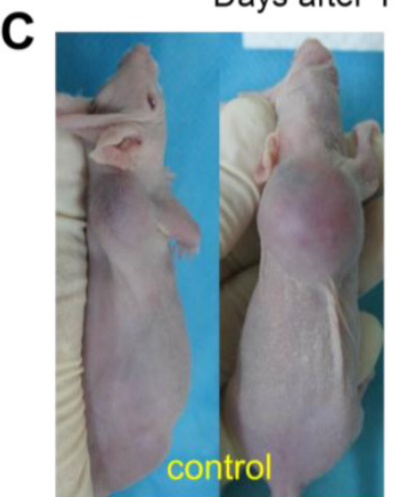

d0

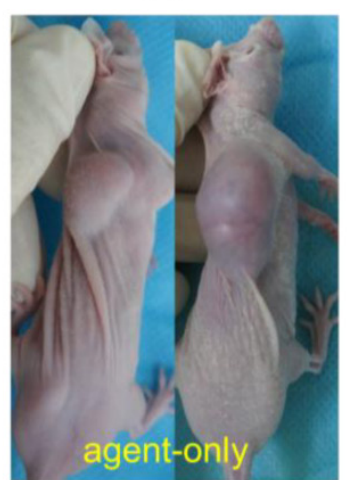

d0

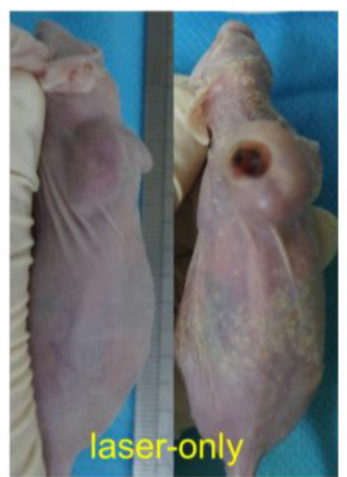

d0

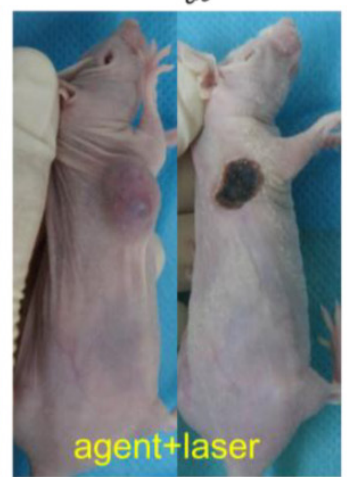

d0 d9

Fig 7. (A) Therapeutic effectiveness expressed as tumor growth rate in each group after one-time treatment in nude mouse xenograft models (data expressed as mean \pm s.d., $n=8$ ); (B) Body weight change of mice in different groups after the treatment (data expressed mean \pm s.d., $n=8$ ); (C) Photographs of representative mice of the four different groups taken pre- and post-treatment, showing the significant therapeutic efficacy of agent+laser group compared to the other groups.

Our previous reported gold nanoshelled microcapsules had been successfully developed to the, multifunctional nanotheranostic agents with innovation of nanocapsule design and construction, functionality integration and xenografed animal mode evaluation. Firstly, instead of large size of microcapsules, the nanoscaled size of nanocapsules with surface PEG modification made the multifunctional agent keep long circulation time in the circulatory system to have great chance to penetrate through blood vessels into the tumor sites for effective diagnostic imaging and therapeutic ablation. Secondly, the integration of MRI with US contrast enhancement capabilities by encapsulation of SPIOs into the PFOB nanocapsule core inside the gold nanoshell could get bimodal US/MRI contrast imaging diagnosis in the same time to provide more accurate complementary information to guide the following tumor ablation. Thirdly, tumor bearing nude mice were used as the animal model for imaging guided tumor ablation. The multifunctional agent was intravenous injected into the mice to allow the nanocapsule aggregation in the tumor sites due to passive targeting. Effective photothermal tumor ablation was successfully carried out under the guidance of US/MRI contrast imaging.

Imaging guided therapy utilized clinical imaging techniques for planning, targeting, monitoring, controlling and assessing treatment response during the therapeutic treatment. Diagnosis, guidance and therapeutics can be fulfilled simultaneously by multifunctional nanomedicine. In our study, the PGS-SP NCs firstly served as a bimodal contrast to enhance both US and MRI imaging for better diagnosis of the tumor to find out the location, size and other information for the planning of the next step procedure. During the photothermal ablation process, the nanocapsules would provide contrast-enhanced and real-time images to guide the NIR laser to irradiate at the right location without damage to normal tissues. The most noticeable feature of the platform is that all the procedures in the whole treatment are noninvasive or minimally invasive to avoid unnecessary risks, and the nanomaterial-based agent could be designed and generated by demand for the best therapeutic efficacy.

\section{Conclusion}

In summary, a multifunctional nanotheranostic agent was successfully constructed by encapsulating SPIOs into PFOB into PLA nanocapsules, followed by the formation of gold nanoshell on the surface and 
PEGylation through Au-S linkage. It was found via MRI that the PEGylated NCs could pass through the vessels feeding the tumor and exhibit high accumulation at tumor sites. The resulting NCs not only provided excellent contrast enhancement for both ultrasound imaging and MRI, but also served as efficient photoabsorbers for NIR photothermal tumor ablation. Thereafter, bimodal contrast imaging guided photothermal therapy was successfully carried out in nude mouse xenograft models. Such a theranostic agent could efficiently kill the tumor cells using the NIR laser irradiation under the guidance of contrast enhance US/MRI, to achieve great therapeutic effectiveness without systemic damage to the animals. Above all, the bimodal imaging guidance could display dynamic complementary information about the tumors to help alter the treatment accordingly with personalization and high efficiency. In the early future, the multifunctional nanotheranostic agent may provide an alternative methodology for noninvasive cancer diagnosis and therapy.

\section{Acknowledgments}

This work was financially supported by National Natural Science Foundation for Distinguished Young Scholars (No. 81225011), State Key Program of National Natural Science of China (Grant No. 81230036) and National Natural Science Foundation of China (No. 21273014).

\section{Competing Interests}

The authors have declared that no competing interest exists.

\section{References}

1. Huang X, El-Sayed IH, Qian W, et al. Cancer cell imaging and photothermal therapy in the near-infrared region by using gold nanorods. J Am Chem Soc. 2006; 128: 2115-20.

2. O'Neal DP, Hirsch LR, Halas NJ, et al. Photo-thermal tumor ablation in mice using near infrared-absorbing nanoparticles. Cancer Lett. 2004; 209: 171-6.

3. Rai P, Mallidi S, Zheng $X$, et al. Development and applications of photo-triggered theranostic agents. Adv Drug Deliver Rev. 2010; 62: 1094-124.

4. Hirsch LR, Stafford RJ, Bankson JA, et al. Nanoshell-mediated near-infrared thermal therapy of tumors under magnetic resonance guidance. P Natl Acad Sci USA. 2003; 100: 13549-54.

5. Loo C, Lowery A, Halas N, et al. Immunotargeted nanoshells for integrated cancer imaging and therapy. Nano Lett. 2005; 5: 709-11.

6. Gobin AM, Lee MH, Halas NJ, et al. Near-infrared resonant nanoshells for combined optical imaging and photothermal cancer therapy. Nano Lett. 2007; 7: 1929-34.

7. Ke H, Wang J, Dai Z, et al. Gold-nanoshelled microcapsules: a theranostic agent for ultrasound contrast imaging and photothermal therapy. Angew Chem Int Ed. 2011; 50: 3017-21.

8. Louie AY. Multimodality Imaging Probes: Design and Challenges. Chem Rev. 2010; 110: 3146-95.

9. Goldberg SN, Grassi CJ, Cardella JF, et al. Image-guided tumor ablation: standardization of terminology and reporting criteria. Radiology. 2005; 235: 728-39.

10. Peters TM. Image-guided surgery and therapy: Current status and future directions. In: Mun SK, editor. Medical Imaging 2001: Visualization, Display, and Image-Guided Procedures. Bellingham: Spie-Int Soc Optical Engineering; 2001;: 1-12.

11. Huber PE, Jenne JW, Rastert R, et al. A new noninvasive approach in breast cancer therapy using magnetic resonance imaging-guided focused ultrasound surgery. Cancer Res. 2001; 61: 8441-7.
12. Hong K, Georgiades CS, Geschwind JF. Technology insight: Image-guided therapies for hepatocellular carcinoma--intra-arterial and ablative techniques. Nat Clin Pract Oncol. 2006; 3: 315-24.

13. Chou SW, Shau $\mathrm{YH}, \mathrm{Wu} \mathrm{PC}$, et al. In vitro and in vivo studies of $\mathrm{FePt}$ nanoparticles for dual modal CT/MRI molecular imaging. J Am Chem Soc. 2010; 132: 13270-8.

14. Cheng H, Nair G, Walker TA, et al. Structural and functional MRI reveals multiple retinal layers. Proc Natl Acad Sci U S A. 2006; 103: 17525-30.

15. McEvoy LK, Fennema-Notestine C, Roddey JC, et al. Alzheimer disease: quantitative structural neuroimaging for detection and prediction of clinical and structural changes in mild cognitive impairment. Radiology. 2009; 251: 195-205.

16. Mulder WJ, Strijkers GJ, van Tilborg GA, et al. Nanoparticulate assemblies of amphiphiles and diagnostically active materials for multimodality imaging. Acc Chem Res. 2009; 42: 904-14.

17. Gao J, Gu H, Xu B. Multifunctional magnetic nanoparticles: design, synthesis, and biomedical applications. Acc Chem Res. 2009; 42: 1097-107.

18. Hrkach J, Von Hoff D, Mukkaram Ali M, et al. Preclinical development and clinical translation of a PSMA-targeted docetaxel nanoparticle with a differentiated pharmacological profile. Sci Transl Med. 2012; 4: 128ra39.

19. Tran TD, Caruthers SD, Hughes $M$, et al. Clinical applications of perfluorocarbon nanoparticles for molecular imaging and targeted therapeutics. Int J Nanomedicine. 2007; 2: 515-26.

20. Diaz-Lopez R, Tsapis N, Fattal E. Liquid perfluorocarbons as contrast agents for ultrasonography and (19)F-MRI. Pharm Res. 2010; 27: 1-16.

21. Pisani E, Tsapis N, Galaz B, et al. Perfluorooctyl Bromide Polymeric Capsules as Dual Contrast Agents for Ultrasonography and Magnetic Resonance Imaging. Adv Funct Mater. 2008; 18: 2963-71.

22. Pisani E, Tsapis N, Paris J, et al. Polymeric nano/microcapsules of liquid perfluorocarbons for ultrasonic imaging: physical characterization. Langmuir. 2006; 22: 4397-402

23. Tong S, Hou S, Zheng Z, et al. Coating optimization of superparamagnetic iron oxide nanoparticles for high T2 relaxivity. Nano Lett. 2010; 10: 4607-13.

24. Laurent S, Forge D, Port M, et al. Magnetic iron oxide nanoparticles: synthesis, stabilization, vectorization, physicochemical characterizations, and biological applications. Chem Rev. 2008; 108: 2064-110.

25. Yoo D, Lee JH, Shin TH, et al. Theranostic Magnetic Nanoparticles. Accounts Chem Res. 2011; 44: 863-74.

26. Yu Y, Sun D. Superparamagnetic iron oxide nanoparticle 'theranostics' for multimodality tumor imaging, gene delivery, targeted drug and prodrug delivery. Expert Rev Clin Pharmacol. 2010; 3: 117-30.

27. Zou P, Yu Y, Wang YA, et al. Superparamagnetic iron oxide nanotheranostics for targeted cancer cell imaging and $\mathrm{pH}$-dependent intracellular drug release. Mol Pharm. 2010; 7: 1974-84.

28. Ghosh D, Lee Y, Thomas S, et al. M13-templated magnetic nanoparticles for targeted in vivo imaging of prostate cancer. Nat Nanotechnol. 2012; 7: 677-82.

29. Lee JH, Huh YM, Jun YW, et al. Artificially engineered magnetic nanoparticles for ultra-sensitive molecular imaging. Nat Med. 2007; 13: 95-9.

30. Brown KR, Natan MJ. Hydroxylamine seeding of colloidal Au nanoparticles in solution and on surfaces. Langmuir. 1998; 14: 726-8.

31. Raynal I, Prigent P, Peyramaure S, et al. Macrophage endocytosis of superparamagnetic iron oxide nanoparticles: mechanisms and comparison of ferumoxides and ferumoxtran-10. Invest Radiol. 2004; 39: 56-63.

32. Rogers WJ, Basu P. Factors regulating macrophage endocytosis of nanoparticles: implications for targeted magnetic resonance plaque imaging. Atherosclerosis. 2005; 178: 67-73.

33. Woodle MC, Engbers CM, Zalipsky S. New amphipatic polymer-lipid conjugates forming long-circulating reticuloendothelial system-evading liposomes. Bioconjug Chem. 1994; 5: 493-6.

34. Barreto JA, O'Malley W, Kubeil M, et al. Nanomaterials: applications in cancer imaging and therapy. Adv Mater. 2011; 23: H18-40.

35. Grabar KC, Allison KJ, Baker BE, et al. Two-dimensional arrays of colloidal gold particles: A flexible approach to macroscopic metal surfaces. Langmuir. 1996; 12: 2353-61.

36. Li SZ, Ma Y, Yue XL, et al. One-pot construction of doxorubicin conjugated magnetic silica nanoparticles. New J Chem. 2009; 33: 2414-8.

37. Ji TH, Lirtsman VG, Avny Y, et al. Preparation, characterization, and application of Au-shell/polystyrene beads and Au-shell/magnetic beads. Adv Mater. 2001; 13: 1253-6.

38. Averkiou M, Powers J, Skyba D, et al. Ultrasound contrast imaging research. Ultrasound Q. 2003; 19: 27-37.

39. Reimer P, Balzer T. Ferucarbotran (Resovist): a new clinically approved RES-specific contrast agent for contrast-enhanced MRI of the liver: properties, clinical development, and applications. Eur Radiol. 2003; 13: 1266-76.

40. Hahn GM, Braun I, Har-Kedar I. Thermochemotherapy: synergism between hyperthermia (42-43 degrees) and adriamycin (of bleomycin) in mammalian cell inactivation. P Natl Acad Sci USA. 1975; 72: 937-40. 